\title{
The effects of cortical or hippocampal damage on behavioral flexibility in the rat
}

\author{
PHILIP TERRY and DAVID A. OAKLEY \\ University College London, London, England
}

\begin{abstract}
Behavioral flexibility in neodecorticate, hippocampal, or control rats was assessed in an obstructed alleyway task. Rats were first trained to dislodge an obstructing ball from a tubular alleyway, either by pushing it into the goalbox or by pulling it into the startbox. At response transfer, the trained response was prevented and the rat had to develop the alternative response in order to clear the alleyway. A series of reversals between responses was then required. Neodecorticate rats were faster than sham-operated rats in transferring from pushing to pulling, but slower on the converse transfer; hippocampals were slower than controls only on transferring from pushing to pulling. All groups completed the reversals competently. Although the neodecorticates demonstrated a unique behavioral profile, their results cannot be explained simply in terms of response bias. Rather, their behavior in the obstructed alleyway task provides evidence of residual flexibility, and it is quite different from that of the hippocampals.
\end{abstract}

Complete surgical removal of neocortex in rats and rabbits does not prevent the acquisition or retention of Pavlovian habits (Oakley \& Russell, 1972, 1977). Indeed, neodecorticate rabbits are fully capable of demonstrating effective Pavlovian discrimination, and can typically reverse their response distribution between positive and negative discriminative stimuli more rapidly than unoperated control animals (Oakley \& Russell, 1974, 1975, 1976). Yet although these results have led to a general acceptance that neodecortication does not impair performance in basic Pavlovian procedures, the situation with regard to instrumental procedures is less clear. The instrumental habit of running a single alleyway is readily acquired under conditions of appetitive reinforcement (Oakley, 1979b), for instance, whereas the acquisition of a leverpress response in the Skinner box sometimes requires the introduction of specialized pretraining procedures that either direct attention to the salient manipulandum (Oakley, 1979a; Oakley \& Russell, 1980) or combine responses to the manipulandum and the reinforcer (Oakley, 1980). However, such manipulations can lead to efficient performance at fixed ratios as high as FR60 (Oakley, 1980). Early reports of neodecorticate response learning in the Skinner box tended to emphasize the rigidity of acquired habits (e.g., Oakley \& Russell, 1978b), and demonstrated a reduced malleability of behavior in reaction to procedural changes. For example, relocation of the lever leads to a deterioration of the leverpress habit

This work was supported by Science and Engineering Research Council Studentship 8231301X to P. Terry. We are grateful to C. Cromarty for preparing the illustrations, and to R. Bunce for technical assistance. Philip Terry is now at the Psychobiology Laboratory, National Institute on Drug Abuse, Addiction Research Center, Baltimore. Please address all correspondence to David A. Oakley, Department of Psychology, University College London, Gower St., London WC1E 6BT, England. and the intrusion of maladaptive responses in neodecorticate rabbits (Oakley \& Russell, 1978a). Tests in other instrumental procedures have indirectly supported the notion of reduced flexibility after cortical damage, as for example, in mazes (e.g., Boyd \& Thomas, 1977; Kolb, Sutherland, \& Whishaw, 1983; Krechevsky, 1935, 1937, 1938; Lashley, 1929; Thomas \& Weir, 1975) and in latchbox tests (e.g., Gentile, Green, Nieburgs, Schmeltzer, \& Stein, 1978; Kolb \& Whishaw, 1983; Lashley, 1935; Thompson, Gallardo, \& Yu, 1984).

Therefore, while studies of neodecorticate learning have led to a progressive devaluation of the role of the neocortex in associative learning, the equation between integrity of the neocortex and response flexibility in reaction to situational change has remained unchallenged. However, the limits of performance attainable by neodecorticate animals-particularly in instrumental procedures-have not yet been ascertained, and there are very few systematic studies of behavioral flexibility per se using modern neodecortication techniques. A more direct approach to the issue has been to test cortex-damaged animals in serial reversal learning tasks. Neodecorticate rats are considerably inferior to controls in reversing position habits in a Grice box, but show improvement over reversals (Kolb \& Whishaw, 1981). Limited serial reversal improvement between spatially separate levers in a Skinner box has also been demonstrated in neodecorticate rabbits, but again performance is markedly inferior to that of controls (Oakley, 1979a).

A recent approach to the issue of response flexibility following brain damage has been provided by Thompson, Harmon, and Yu (1984a, 1984b). They follow Riopelle's (1967, p. 253) prescription for response flexibility: "the ability rapidly to discard unsuccessful responses and to attempt new ones, until the correct one is found." Using three different kinds of climbing detour problem, Thomp- 
son, Harmon, and Yu (1984b) found that damage to the hippocampus, frontal (motor) cortex, or parietal cortex (but not occipital cortex) caused deficits on the first trial, requiring a detour solution, but that subsequent habit formation progressed adequately.

A similarly more direct approach by Terry, Herbert, and Oakley (1989) produced a discrepant result. Neodecorticate and sham-operated rats were tested in a variant of the Morgan obstructed alleyway apparatus (Einon, Morgan, \& Will, 1980; Morgan, 1973; Morgan, Einon, \& Morris, 1977). In order to gain access to reinforcement, the rats were trained to dislodge a foam rubber ball from a cylindrical alleyway by pushing it through the alleyway and into the goalbox. On a response transfer test, the pushing response was prevented by blocking the forward movement of the ball. To clear the alleyway, the rats now had to pull the ball into the startbox. Surprisingly, the neodecorticates were considerably quicker than the shams in successfully developing and executing the novel response. They subsequently reversed between responses proficiently. In a second experiment, the rats were trained first to use the pulling response and then transferred to the pushing response. This time the neodecorticates showed a marked transfer decrement, but subsequent response reversals were again proficient. This result could not be explained by assuming a propensity for pulling behavior on the part of the neodecorticates, since these rats also had considerable difficulty in initially acquiring the pull habit.

Our aim in the present experiment was to examine further this anomalous pattern of behavioral flexibility by testing both push-trained and pull-trained rats in a single experiment. A shorter alleyway was used, and a ball position in the center of the alleyway was adopted as the site of response transfer for both groups. More finely graduated training procedures were used in order to facilitate the training specifically of pull responding on the part of the neodecorticates, and thus to help eliminate the "pull overtraining" received by the pull-trained neodecorticates in the study by Terry et al. (1989).

In addition to neodecorticated and sham-operated rats, two other lesion groups were included for testing: a group receiving hippocampal damage and an associated cortical control group receiving limited damage to the parietal cortex. The hippocampus was chosen because its associated behavioral syndrome has often been interpreted in terms of impaired response control, and similarities between the consequences of cortical and hippocampal damage have been repeatedly observed (by, e.g., Kolb, Nonneman, \& Singh, 1974; Numan, 1978; Sutherland, Kolb, \& Whishaw, 1982; and Teitelbaum, 1964). Hippocampal injury retards extinction (see, e.g., Niki, 1965) and reversal performance (see, e.g., Kimble \& Kimble, 1965), and the syndrome has been characterized by its narrowing of response variability (see, e.g., Devenport, Hale, \& Stidham, 1988; Hirsh, 1970). The aspects of per- formance of particular interest at present are the points at which any hippocampal deficit is manifested-whether at response training, transfer, or reversal-and whether the transfer profiles follow the sham or the neodecorticate pattern. It might be predicted that the hippocampals would show impaired transfer and reversal performance. Indeed, Einon et al. (1980) have already demonstrated a mild hippocampal impairment on the pull-to-push transfer. A pull acquisition impairment was also found. However, their procedure differed in several respects from that used in the present task.

Finally, the previous study originated from an interpretation of the task as a test of problem-solving ability, emphasizing performance on the transfer trial. In the present experiment, we developed the scope of analysis, undertaking a more detailed examination of response changes during and immediately after transfer, and over subsequent reversals.

\section{METHOD}

\section{Subjects and Surgery}

There were 10 male rats (hooded, P.V.G. strain) in each lesion condition. Their mean age at surgery was 84.5 days $(S D=34.8$ days); their mean postoperative recovery period was 96.4 days ( $S D=25.4$ days). These factors were balanced across lesion groups, and each group included 2 rats with a long recovery interval (143-146 days). The rats were tested during the light period of a 12:12-h light:dark cycle.

All surgery was done with administration of pentobarbitone sodium (Sagatal, $50 \mathrm{ml} / \mathrm{kg}$ ) anaesthesia. Neodecortication was achieved in a single stage by pial stripping (Meyer \& Meyer, 1971; Oakley, 1979b). Hippocampal lesions were produced by a standard aspiration lesion of the dorsal two thirds of the hippocampus. Because this inevitably involves the removal of up to $10 \%$ of the overlying (primarily parietal) neocortex, a cortical control condition was included, in which rats received aspiration removal of neocortex equivalent to that removed in the hippocampals. Sham-operated control rats underwent all surgical procedures common to the other rats, but they received no bone or tissue removal; the skull was scored lightly over the parietal cortex with the drill. Following surgery, all rats received a $0.4-\mathrm{ml}$ intramuscular injection of Propen penicillin, and a 10-ml subcutaneous injection of dextrose solution.

\section{Apparatus}

The apparatus was derived from Morgan (1973); it is illustrated in Terry et al. (1989). Two metal compartments (start- and goalbox, $20 \times 20 \times 25 \mathrm{~cm}$ high, one wall of clear Perspex) were connected at floor level by a tubular alleyway (also of clear Perspex). The alleyway was $9.5 \mathrm{~cm}$ in diameter, with a length of $12.8 \mathrm{~cm}$ (vs. $26.5 \mathrm{~cm}$ previously). The position of the obstructing rubber ball (diameter, $7.8 \mathrm{~cm}$ ) was determined by locking a sliding peg (width, $0.4 \mathrm{~cm}$, extending $2.7 \mathrm{~cm}$ into the alley) at any point along a longitudinal slit (length, $10.8 \mathrm{~cm}$; width, $0.5 \mathrm{~cm}$ ) cut in the alleyway roof. A graduated strip along one side of the slit marked off 10 peg positions $(0.65-\mathrm{cm}$ separation) for pull response training. The first was $2.9 \mathrm{~cm}$ from the entrance, the last was $8.8 \mathrm{~cm}$ from the entrance. A second graduated strip, on the other side of the slit, marked off 10 positions for push training. The first position was $2.9 \mathrm{~cm}$ from the exit, and the last was $8.8 \mathrm{~cm}$ from the exit. The 10th (stabilization) peg position for one response was the 
transfer peg position for the other response. This final position was the same for both training conditions. A wooden block was placed under the start- or goalbox to tilt the alleyway at an angle of $4^{\circ}$ against the direction of the required response.

The delivery of water reinforcement was solenoid-controllable, $0.1 \mathrm{ml}$ of water being forced through a spout in the back wall of the goalbox. The spout was $9.5 \mathrm{~cm}$ above the floor, extending $1.5 \mathrm{~cm}$ into the box and $1.2 \mathrm{~cm}$ downwards. The water dropped into a cup (surface area, $4.5 \mathrm{~cm}$; maximum depth, $0.3 \mathrm{~cm}$ ) fixed to the rear wall $2 \mathrm{~cm}$ above floor level.

A centisecond scaler measured total trial time, and two similar scalers (all Campden instruments) recorded push-type and pull-type contacts with the obstructing ball (see below). Connections to two integer counters allowed cumulative measurement of the numbers of contacts made.

\section{Procedure}

All rats were on a 23-h water deprivation schedule starting the day before the first test. Water was available for $30 \mathrm{~min}$ following each test; consumption rates were monitored. All sessions were on consecutive days. The first was a 30 -min familiarization period, in which the rat was allowed to explore the apparatus; the ball was absent. Water $(0.1 \mathrm{ml})$ was dispensed into the cup at 40 -sec intervals following drinking episodes.

Familiarization was followed by three sessions of alleyway pretraining. Here, the animal ran the unobstructed alleyway for water reinforcement. Each session comprised 30 trials. Total run time for each trial was measured from when the rat entered the startbox to the moment it contacted the water cup. The intertrial interval was approximately $20 \mathrm{sec}$, and it remained so throughout the study. Next, there were two sessions of response training, in which half the animals in each group learned to push the ball out of the alleyway, and half learned to clear the alleyway by pulling the ball. For the first session, the apparatus was not wedged against the direction of response execution; for the second, the wedge was inserted. The sessions were otherwise identical. There was a minimum of 25 trials, but no set maximum. For the first 5 trials, the ball was present in either the goalbox (push-trained animals) or the startbox (pull-trained animals), being moved systematically closer to the alleyway exit/entrance and completely obscuring it on the 5th trial. There then followed 2 trials at each of the 10 ball positions. From this point on, the locking pin was placed so that only the designated response would allow removal of the ball from the alleyway. If the rat failed to clear the ball within $300 \mathrm{sec}$ of entering the apparatus, a retraining trial was given with the ball at its previous position. After successful completion of the second response training session, there were two 30-trial sessions of response stabilization, on each trial of which the rat had to remove the ball from the terminal (central) ball position, using the trained response.

The response transfer session consisted of 20 trials. For the first 5 trials, the rat could clear the alleyway using the trained response; on the subsequent 15 trials, the untrained alternative response was necessary for successful alleyway clearance. Thus the 6th trial was the crucial response-transfer trial. To enforce the adoption of a novel strategy, the locking pin was moved from the terminal position for the trained response to the terminal position for the untrained response. The ball remained in the same place in the alleyway; the wedge tilting the apparatus was relocated to the opposite end. On unsuccessful trials, the rat was removed from the apparatus after $300 \mathrm{sec}$, and the scores were noted for that period. The rat was returned to the apparatus on both successful and unsuccessful trials after $20 \mathrm{sec}$. If 15 successful runs using the nontrained response were not completed within $35 \mathrm{~min}$, the session was terminated and continued the next day, to a maximum of 20 unsuccessful transfer sessions. Ten reversal sessions followed the initial transfer ses- sion(s), each structured similarly. Thus for the first 5 trials of the session, the appropriate response was the one required on the final 15 trials of the previous session; reversal between responses therefore always occurred on the 6th trial.

The following measures were taken: total alleyway run time (latency between entering the apparatus and contacting the water cup), ball contact time, and number of contacts executed. The observer made these measurements by depressing buttons operating the scalers. The contact scores were recorded separately for push-type and pull-type responses. Paw contacts were almost exclusively scored as pulls, the exceptions being when force was clearly being directed forwards; snout/head contacts were scored as pushes, except when biting or tugging was observed. On transfer, any response dissimilar to that developed during training was scored as an untrained response. Contacts were only scored when they occurred in the alleyway.

To assess observer reliability, a pilot study was performed with unoperated rats. Behavior was recorded on video tape and measured by two other experienced observers; their measures were always in close agreement with those of the experimenter.

\section{Statistical Analyses}

The training variable, with the two levels of push-trained and pull-trained will be referred to as task. All analyses were by analysis of variance, with two levels of the factor task and four levels of the factor lesion. Planned comparisons within each level of task were performed to compare shams with neodecorticates, and cortical controls with hippocampals.

\section{RESULTS}

\section{Histology}

After the experiment, the rats received a lethal dose of pentobarbitone sodium anaesthetic and were perfused intracardiacally with physiological saline followed by $10 \%$ formol saline. The brains were removed and embedded in gelatine. Frozen coronal sections were cut at $40 \mu$ thickness, and every 7 th section was mounted and stained with cresyl violet. The lesions were drawn from microscopic examination of these slides onto a series of standard coronal sections. Figure 1 presents coronal sections reconstructing a representative lesion in each group.

Group mean percentages of neocortical or hippocampal removal were: for the neodecorticates, $97.2 \%$ ( $S D=$ $0.9 \%$ ) of the neocortex; for the hippocampals, $72.0 \%$ (SD $=4.8 \%)$ of the hippocampus and $4.8 \%(S D=1.0 \%)$ of the neocortex; for the cortical controls, $5.8 \%$ ( $S D=$ $0.8 \%$ ) of the neocortex. No brain damage was evident in any of the sham-operated rats. Although the neodecortications were uniformly large, there was no direct subcortical damage in any of the brains. However, 1 (pushtrained) showed some damage to the entorhinal cortex; the lesion also extended into the pyriform cortex, as was also the case for 2 others (1 push-trained and 1 pulltrained). Some unintended subcortical injury was evident in the hippocampal group: unilateral damage to the lateral thalamus was present in 3 ( 2 push-trained, 1 pull-trained). Slight pretectal damage was evident in 2 (1 in each level of task). None of these additional injuries was later found to be associated with differences in performance. 


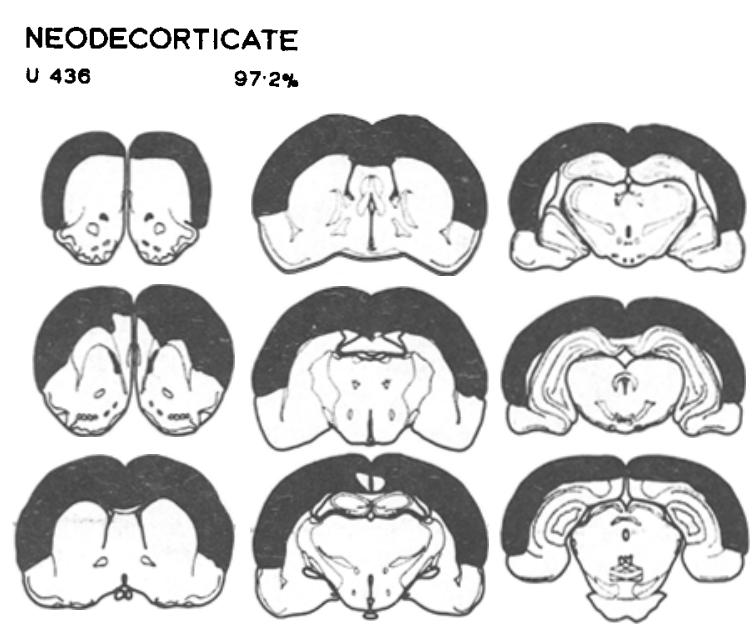

HIPPOCAMPAL

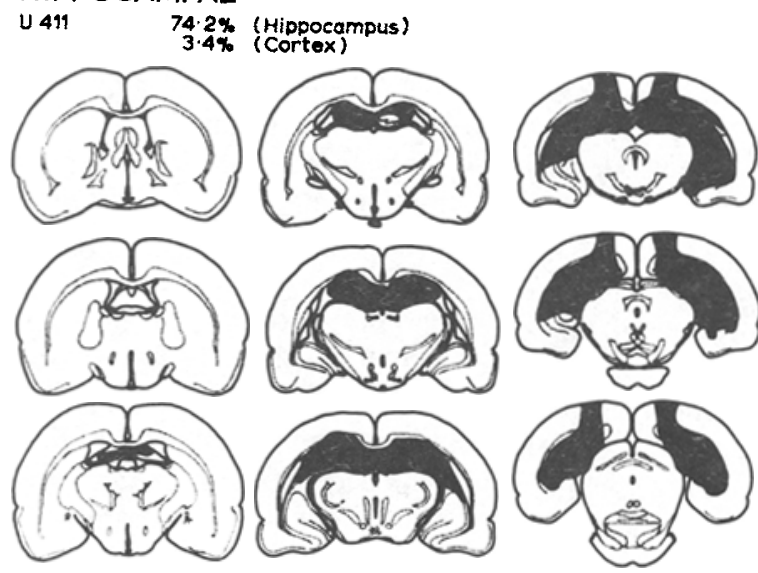

CORTICAL CONTROL U 443 5.9\%

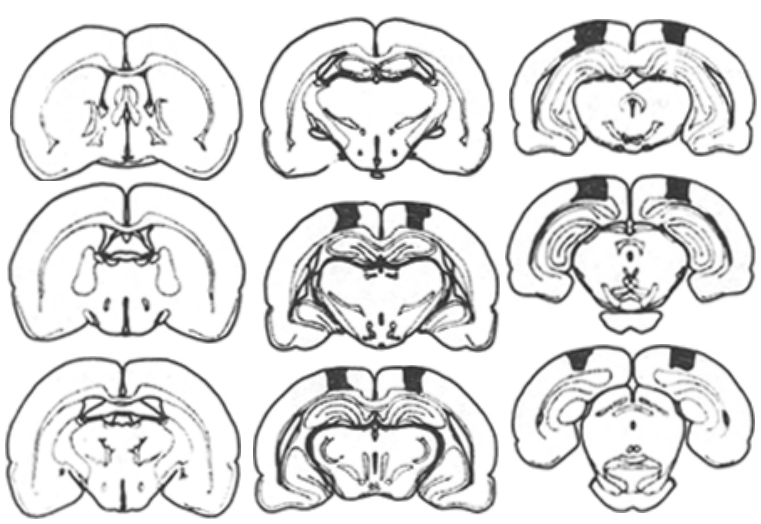

Figure 1. Coronal reconstructions of tissue loss for 1 representative subject of each lesion condition receiving tissue damage.

\section{Water Intake and Body-Weight Changes}

There were no reliable differences between groups in water intake quantities, nor in body-weight changes during the experiment. However, there was an overall difference in absolute body weight between shams and neodecorticates throughout: shams, $423.6 \mathrm{~g}(S D=51.6 \mathrm{~g})$; neodecorticates, $325.9 \mathrm{~g}(S D=28.9 \mathrm{~g})[F(1,18)=27.3$, $p<.001]$. Mean weights for the cortical controls and hippocampals were $409.6 \mathrm{~g}(S D=49.3 \mathrm{~g})$ and $382.4 \mathrm{~g}$ $(S D=49.3 \mathrm{~g})[F(1,18)=1.48, p>.05]$.

\section{Alleyway Pretraining}

There was an overall difference between lesion groups, primarily attributable to fast hippocampal run speeds. Subject median run times on the final session were logarithmtransformed (base 10) before analysis. The factor of lesion was significant $[F(3,32)=9.59, p<.005]$, but the factor of task and the interaction between factors were not [task: $F(1,32)=0.03, p>.05$; task $\times$ lesion: $F(3,32)=0.22, p>.05]$. The group means of medians were, for the shams, $4.1 \mathrm{sec}(S D=1.2 \mathrm{sec})$; for the neodecorticates, $3.2 \mathrm{sec}(S D=0.7 \mathrm{sec})$; for the cortical controls, $3.6 \mathrm{sec}(S D=3.6 \mathrm{sec})$; and for the hippocampals, $1.7 \mathrm{sec}(S D=0.4 \mathrm{sec})$. Post hoc comparison between cortical controls and hippocampals revealed significantly faster hippocampal run speeds in each task condition [Task 1: $F(1,32)=5.79, p<.05$; Task 2: $F(1,32)=$ $8.211, p<.01]$.

\section{Response Training and Stabilization}

There was no difference between lesion groups in numbers of training trials to criterion, but during stabilization, the neodecorticates were slower in executing the appropriate responses [for training trials to criterion, task: $F(1,32)=2.24, p>.05$; lesion: $F(3,32)=0.51$, $p>.05$; task $\times$ lesion: $F(3,32)=0.65, p>.05$ ]. Thus there was no repeat of the severe neodecorticate pullacquisition impairment found in the previous experiment (Terry et al., 1989).

On the final session of response stabilization, differences between task conditions and lesion groups began to emerge on both time measures (median total time and median contact time). For contact time (CT), the more important measure, there were highly significant main effects of task $[F(1,32)=32.94, p<.005]$ and lesion $[F(3,32)=7.26, p<.005]$, but there was no significant interaction of task $\times$ lesion $[F(3,32)=0.68$, $p>.05]$. The same pattern was true of total trial time (TT). The task effect simply reflects the greater time taken in pulling the ball than in pushing it. The only significant differences emerging from planned comparisons of lesion groups at each level of the task factor were for the comparisons between shams and neodecorticates (both measures). For CT (push), the neodecorticate mean was $0.6 \mathrm{sec}(S D=0.5 \mathrm{sec})$; the sham mean was $0.2 \mathrm{sec}(S D$ $=0.1 \mathrm{sec})$. This difference was significant $[F(1,32)=$ 
Table 1

Arithmetic Group Means, with Standard Deviations, of All Response Measures on the Critical Transfer Trial

\begin{tabular}{lcrrrrr}
\hline & & \multicolumn{2}{c}{$\begin{array}{c}\text { Task 1 } \\
\text { (Push-Trained) }\end{array}$} & & \multicolumn{2}{c}{$\begin{array}{c}\text { Task 2 } \\
\text { (Pull-Trained) }\end{array}$} \\
\cline { 3 - 4 } \cline { 6 - 7 } Lesion Group & Score & \multicolumn{1}{c}{$M$} & \multicolumn{1}{c}{$S D$} & & \multicolumn{1}{c}{$M$} & \multicolumn{1}{c}{$S D$} \\
\hline Sham & TT & 313.5 & 239.4 & & 28.5 & 17.1 \\
& CT & 31.5 & 11.1 & & 6.0 & 6.3 \\
Neodecorticates & NC & 34.4 & 12.4 & & 4.2 & 2.4 \\
& TT & 71.4 & 69.6 & & 903.5 & 1537.1 \\
& CT & 7.7 & 5.7 & & 53.5 & 54.2 \\
Cortical controls & NC & 12.4 & 8.2 & & 40.2 & 45.8 \\
& TT & 345.0 & 390.5 & & 27.6 & 27.3 \\
& CT & 33.0 & 23.3 & & 6.7 & 9.0 \\
Hippocampals & NC & 31.2 & 20.5 & & 4.2 & 3.3 \\
& TT & 4067.5 & 2622.9 & & 21.2 & 15.6 \\
& CT & 137.4 & 127.0 & & 4.8 & 4.1 \\
& NC & 130.6 & 99.2 & & 5.4 & 3.5 \\
\hline
\end{tabular}

Note- $\mathrm{TT}=$ total time, $\mathrm{CT}=$ contact time, $\mathrm{NC}=$ number of contacts .

$8.33, p<.01]$. For the pull task, the mean neodecorticate CT was $0.9 \mathrm{sec}(S D=0.4 \mathrm{sec})$, and the mean sham CT was $0.4 \mathrm{sec}(S D=0.1 \mathrm{sec})$. This comparison was also significant $[F(1,32)=6.12, p<.05]$. Thus, the neodecorticates were slower in the successful execution of both responses. The effect was therefore not specific to the pulling response as it had been in the previous experiment, and the effect size was small. No differences emerged from comparisons between cortical controls and hippocampals.

\section{Response Transfer}

Of the 40 animals tested on response transfer, 5 failed to change response successfully on the first transfer session. One of these was a pull-trained neodecorticate transferring to pushing. This rat took 3 test sessions to clear by pushing, but then took a further 11 sessions to finish all of the 15 push trials required for completion of the original transfer session. The other 4 rats demonstrating severe difficulties in transfer were all push-trained hippocampals transferring to pull $(5,3,3$, and 2 sessions required).

Group means of TT, CT, and numbers of contacts (NC) on the critical transfer trial are presented in Table 1. The results of analyses of variance on the logarithmtransformed scores are presented in Table 2. The key results are summarized below.

1. Neodecorticates are faster than shams in transferring from pushing to pulling, but they are slower in transferring from pulling to pushing. The pattern for the score CT is as in the previous study (Terry et al., 1989). This crossover accounts for the absence of an overall significant effect of lesion, and for the strongly significant interaction. The planned comparisons confirm that these differences are statistically significant (Table 2). A similar pattern emerges for the other two measures taken (TT and $\mathrm{NC}$ ).

2. Hippocampals are severely impaired in comparison with the cortical controls only on the transfer from pushing to pulling. Both groups follow the sham pattern in producing longer scores on the transfer from push to pull (only the neodecorticates show the opposite tendency). These differences are illustrated in Figure 2.

3 . The neodecorticates only perseverate when they are pull-trained, and they produce similar rates of novel response in both tasks; the hippocampal transfer deficit is not due solely to perseveration.

As is noted, the contact scores were partitioned into push-type and pull-type components; these were then sorted into perseverative contacts (responses of the trained type) and novel contacts (any responses that differed from the trained type). The two categories were analyzed separately. The results for numbers of perseverative and novel contacts (Table 3) generally follow the overall pattern.

Table 2

Summary of $2 \times 4$ Analyses of Variance Performed on All Response Measures on the Critical Transfer Trial

\begin{tabular}{|c|c|c|c|c|}
\hline \multirow[b]{2}{*}{ Comparison } & \multirow[b]{2}{*}{$d f$} & \multicolumn{3}{|c|}{$F$ Value and Significance Level } \\
\hline & & Contact Time & Total Time & No. Contacts \\
\hline$\overline{\text { Task }}$ & 1,32 & $22.25 \dagger$ & $33.49 \dagger$ & $51.17 \dagger$ \\
\hline Lesion & 3,32 & $0.86 \ddagger$ & $2.57 \ddagger$ & $2.96 *$ \\
\hline Task $\times$ lesion & 3,32 & $14.10 \dagger$ & $19.16 \dagger$ & $15.59 *$ \\
\hline \multicolumn{5}{|l|}{ Planned Contrasts } \\
\hline \multicolumn{5}{|l|}{ Shams vs. neodecorticates } \\
\hline Task 1 & 1,32 & $7.12^{*}$ & $7.15^{*}$ & $6.50^{*}$ \\
\hline Task 2 & 1,32 & $16.00 \dagger$ & $13.94 \dagger$ & $21.13 \dagger$ \\
\hline \multicolumn{5}{|c|}{ Cortical controls vs. hippocampals } \\
\hline Task 1 & 1,32 & $4.41^{*}$ & $16.05 \dagger$ & $9.20 \dagger$ \\
\hline Task 2 & 1,32 & $0.09 \ddagger$ & $0.12 \ddagger$ & $0.40 \ddagger$ \\
\hline \multicolumn{5}{|l|}{ Interaction } \\
\hline $\begin{array}{l}\text { Shams vs. neodecorticates } \\
\text { (Both levels of task) }\end{array}$ & 1,32 & $22.24 \dagger$ & $20.52 \dagger$ & $25.54 \dagger$ \\
\hline
\end{tabular}




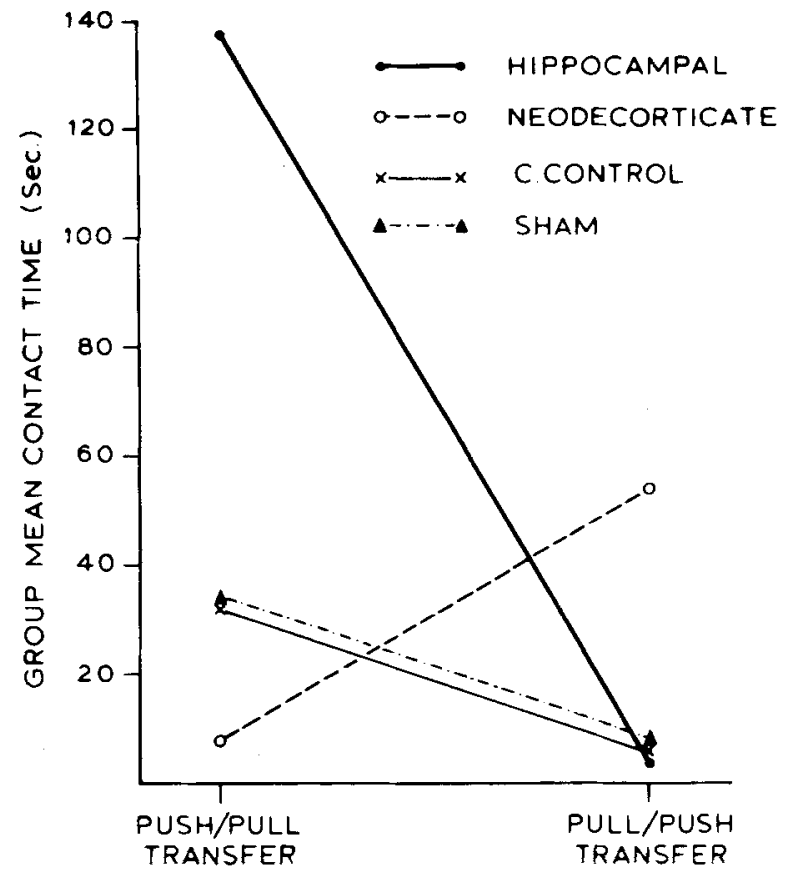

Figure 2. Mean contact times for each lesion group for both types of response transfer.
The effects of task at lesion reflect the fact that each lesion type except the neodecorticates produced significantly more perseverative and novel responses under push/pull than under pull/push conditions. The anomalous neodecorticate result reflects low rates of novel responding in both tasks (see below). The comparison results for shams as opposed to neodecorticates are a consequence of sham perseveration on push/pull transfer, as opposed to greater neodecorticate perseveration and novel responding on the opposite transfer (Figure 3).

The comparisons of cortical controls with hippocampals on push-to-pull transfer were also significant. Surprisingly, the results for novel contacts reflect a very high rate of novel (but unsuccessful) contacts on the part of the hippocampals (also Figure 3).

A post hoc analysis of neodecorticate NC was performed to test whether the crossover of novel and perseverative responses between transfer tasks was significant. The data were selected out and analyzed by a split-plot $2 \times 2$ ANOVA, the factors being task and response type (perseverative or novel). Task was not significant $[F(1,8)=1.78, p>.05]$, but response type and the interaction of task $\times$ response type were both significant [response type: $F(1,8)=14.72, p<.005$; task $\times$ response type: $F(1,8)=52.71, p<.005$ ]. This strong interaction arises because although novel NC differs lit-

Table 3

Summary of $2 \times 4$ Analyses of Variance Performed on Numbers of Contacts Emitted on the Critical Transfer Trial

\begin{tabular}{|c|c|c|c|}
\hline \multirow[b]{2}{*}{ Comparison } & \multirow[b]{2}{*}{$d f$} & \multicolumn{2}{|c|}{$F$ Value and Significance Level } \\
\hline & & $\begin{array}{l}\text { No. Contacts } \\
\text { Perseverative } \\
\end{array}$ & $\begin{array}{c}\begin{array}{c}\text { No. Contacts } \\
\text { Novel }\end{array} \\
\end{array}$ \\
\hline $\begin{array}{l}\text { Task } \\
\text { Lesion } \\
\text { Task } \times \text { lesion }\end{array}$ & $\begin{array}{l}1,32 \\
3,32 \\
3,32\end{array}$ & $\begin{array}{r}32.30 \dagger \\
1.94 \ddagger \\
17.01 \dagger\end{array}$ & $\begin{array}{r}84.03 \dagger \\
3.68^{*} \\
7.63 \dagger\end{array}$ \\
\hline $\begin{array}{l}\text { Lesion at Task } 1 \\
\text { Lesion at Task } 2\end{array}$ & $\begin{array}{l}3,32 \\
3,32\end{array}$ & $\begin{array}{l}9.24 \dagger \\
9.71 \dagger\end{array}$ & $\begin{array}{l}6.98 \dagger \\
4.34^{*}\end{array}$ \\
\hline $\begin{array}{l}\text { Task at shams } \\
\text { Task at cortical controls } \\
\text { Task at hippocampals } \\
\text { Task at neodecorticates }\end{array}$ & $\begin{array}{l}1,32 \\
1,32 \\
1,32 \\
1,32\end{array}$ & $\begin{array}{l}18.94 \dagger \\
17.54 \dagger \\
36.50 \dagger \\
10.34 \dagger\end{array}$ & $\begin{array}{r}29.19 \dagger \\
22.66 \dagger \\
54.45 \dagger \\
0.63 \ddagger\end{array}$ \\
\hline $\begin{array}{l}\text { Shams vs. neodecorticates } \\
\text { Task } 1 \\
\text { Task } 2\end{array}$ & $\begin{array}{l}1,32 \\
1,32\end{array}$ & $\begin{array}{r}9.18 \dagger \\
20.59 \dagger\end{array}$ & $\begin{array}{l}3.23 \ddagger \\
7.92 \dagger\end{array}$ \\
\hline $\begin{array}{l}\text { Cortical controls vs. hippoca } \\
\text { Task } 1 \\
\text { Task } 2\end{array}$ & $\begin{array}{l}1,32 \\
1,32\end{array}$ & $\begin{array}{l}5.85 * \\
0.32 \ddagger\end{array}$ & $\begin{array}{r}12.97 \dagger \\
0.97 \ddagger\end{array}$ \\
\hline Interaction & & & \\
\hline $\begin{array}{l}\text { Shams vs. neodecorticates } \\
\text { (both levels of task) }\end{array}$ & 1,32 & $28.63 \dagger$ & $10.63 \dagger$ \\
\hline
\end{tabular}

Note-Responses were categorized as perseverative (of the trained type), or nonperseverative (novel, of an untrained type). All scores were $\log _{11}$ transformed before analysis. ${ }^{*} p<.05 . \quad \dagger p<.005$. $\ddagger p>$.05, n.s. 
tle across tasks (and is similar to perseverative NC in Task 1), perseverative NC on pull/push transfer is very much greater than on push/pull transfer. Thus the neodecorticates only perseverate on the pull response.

4. All lesion groups demonstrate increasing clearance proficiency over the course of the transfer session. This is evident from Figure 4, plotting total CT against trials (transfer and posttransfer) for each task condition and each lesion type.

Interestingly, the neodecorticates in the push/pull condition still show an improvement towards asymptote despite their abnormally rapid transfer to the novel response on the transfer trial. Thus the novel response adopted appears to be modifiable. Plots of partitioned push and pull NCs over the same 15-trial period failed to reveal anything more than plots of total CT, and so they will not be given here.

\section{Reversals}

All lesion groups demonstrated performance improvements over reversals. Mean total CT for each lesion type on the critical response-shift trial is plotted over the 11 reversal sessions (transfer plus 10 subsequent reversals) and for both transfer tasks in Figure 5. In all groups except the neodecorticates, the transfer session CT for pushtrained animals is disproportionately high, but performance on the next reversal is almost at asymptote and subsequent improvement only slight. In the pull-trained animals, there is also clear evidence of improvement over the early reversals. Here, the neodecorticates show a very high transfer session CT dropping to near-asymptote on the next reversal, but with a mild recurrence of the initial transfer deficit on Reversal 2 (which, like the initial transfer, requires a shift from pull to push). Thereafter, performance begins to level off. Mean total CT for the push-trained neodecorticates starts from a low mean transfer score and declines steadily across reversals. On most reversals, mean neodecorticate $\mathrm{CT}$ is a little higher than that of other lesion types. In contrast, the hippocampal plots are not manifestly different from those of the shams or cortical controls, the main difference being the abnormally high score on the initial transfer after push train-

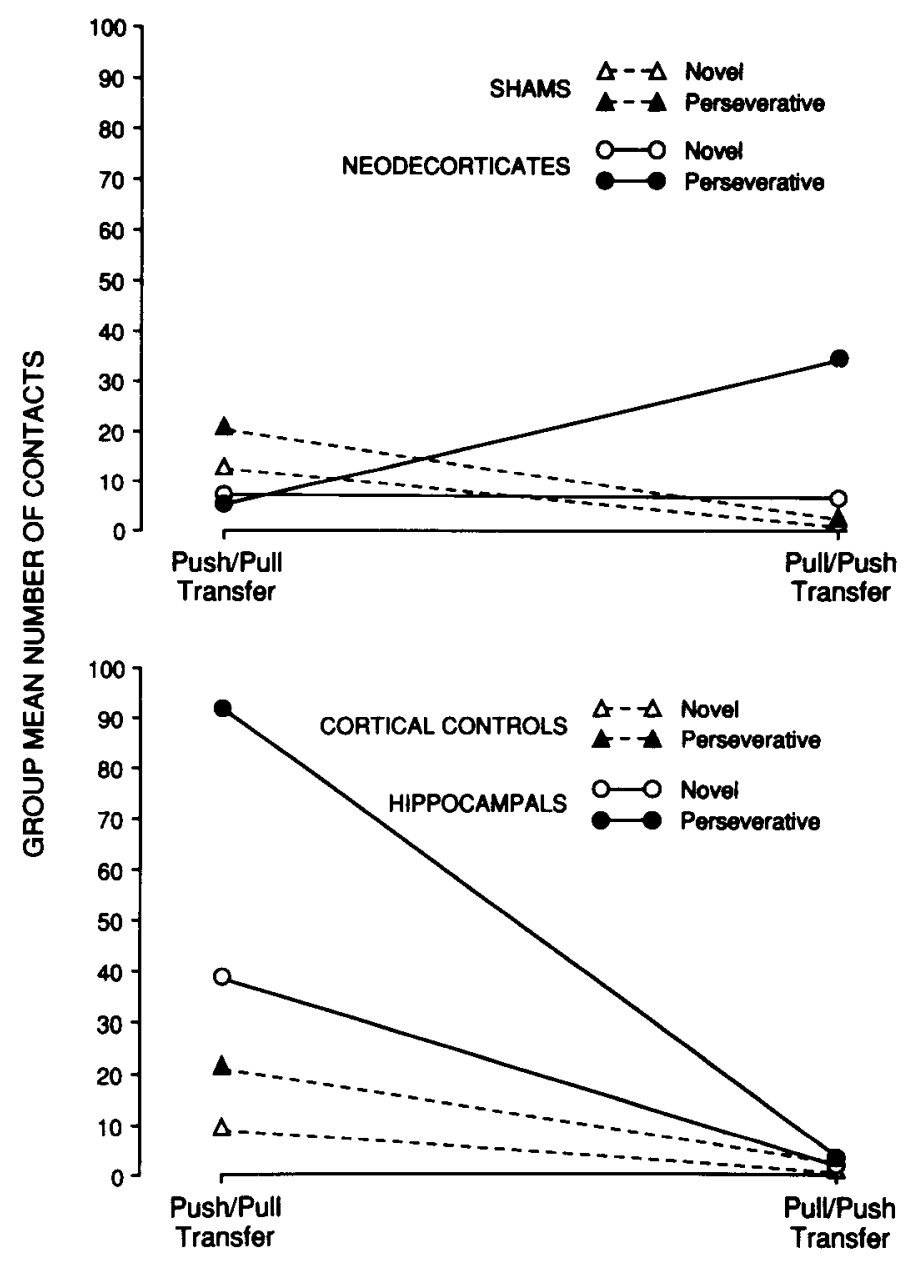

Figure 3. Mean numbers of contacts, sorted into perseverative or novel, for each lesion group for both types of response transfer. 


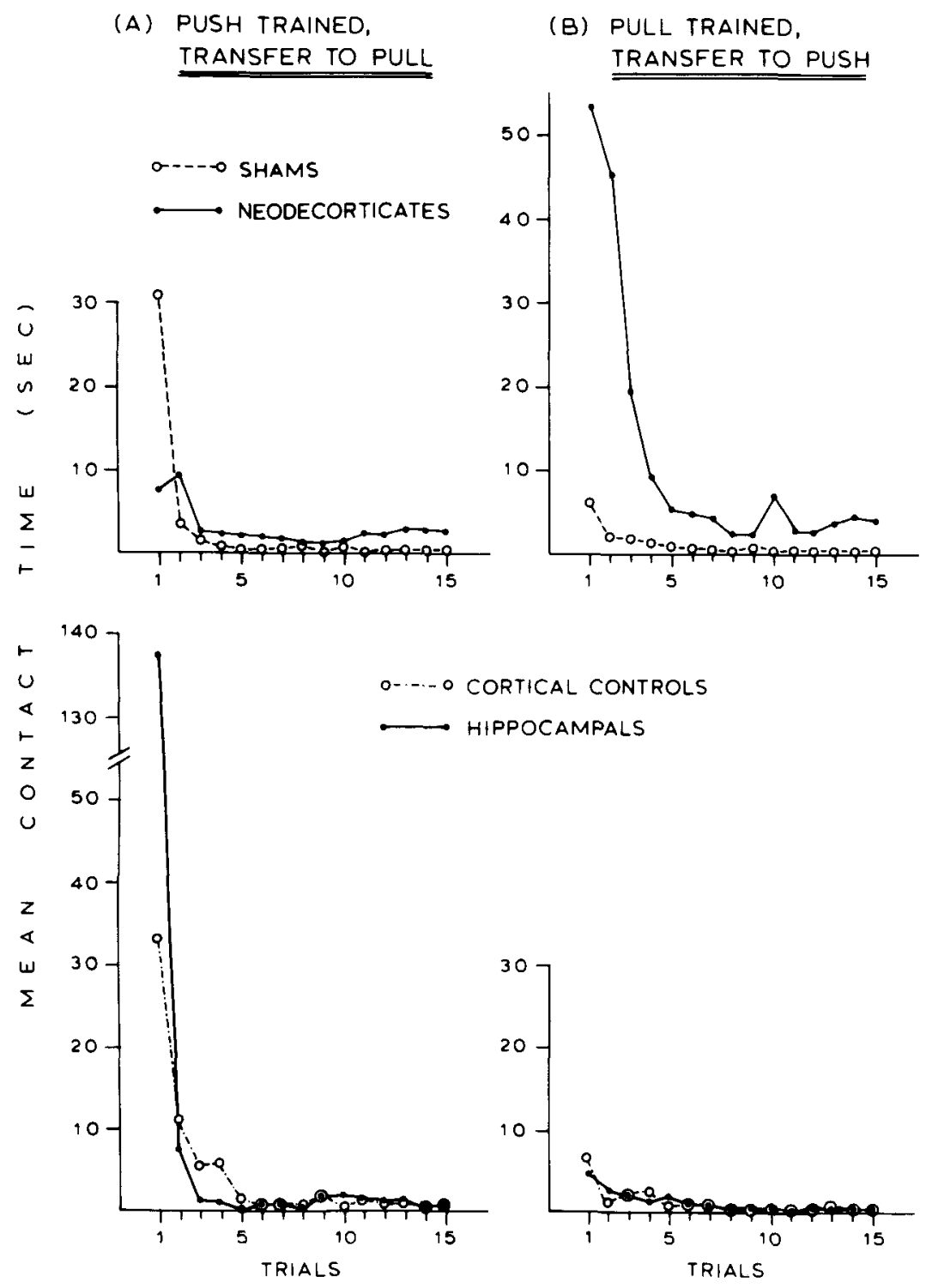

Figure 4. Mean contact times for each lesion group over the first 15 trials requiring the adoption of a novel response. Trial 1 here corresponds to the critical transfer trial.

ing. The neodecorticate profiles are entirely congruent with those reported by Terry et al. (1989).

Trends in partitioned push and pull scores over reversals will not be presented, since they do not shed further light on the learning processes occurring (but see below).

\section{Within-Session Error Rates over Reversals}

Neodecorticates were able to systematically reduce the overall frequencies of erroneous responses over reversal sessions. For the transfer session and each subsequent reversal, the total number of inappropriate responses emitted on the critical response-shift trial and the following 14 trials requiring the shifted-to response were summed to provide the total number of erroneous responses per session. These scores will be referred to as errors. In- dividual differences in response preference developed, and this made the derivation of group mean plots an equivocal exercise. However, the neodecorticate plots revealed a much greater degree of consistency than was apparent for any of the other lesion types. Following original push training (Figure 6), the neodecorticates showed a diminution in push errors over reversals, with rates of pull errors rapidly rising to much higher levels. After pull training (also Figure 6), the clear general trend is for pull errors to decline systematically, with push errors occurring at a lower and relatively stable rate. Thus, there is a strong indication of an improving ability to eliminate errors of each pretrained response-a feature not consistently apparent for other lesion groups. Interestingly, there is no indication of improving suppression of pull errors 


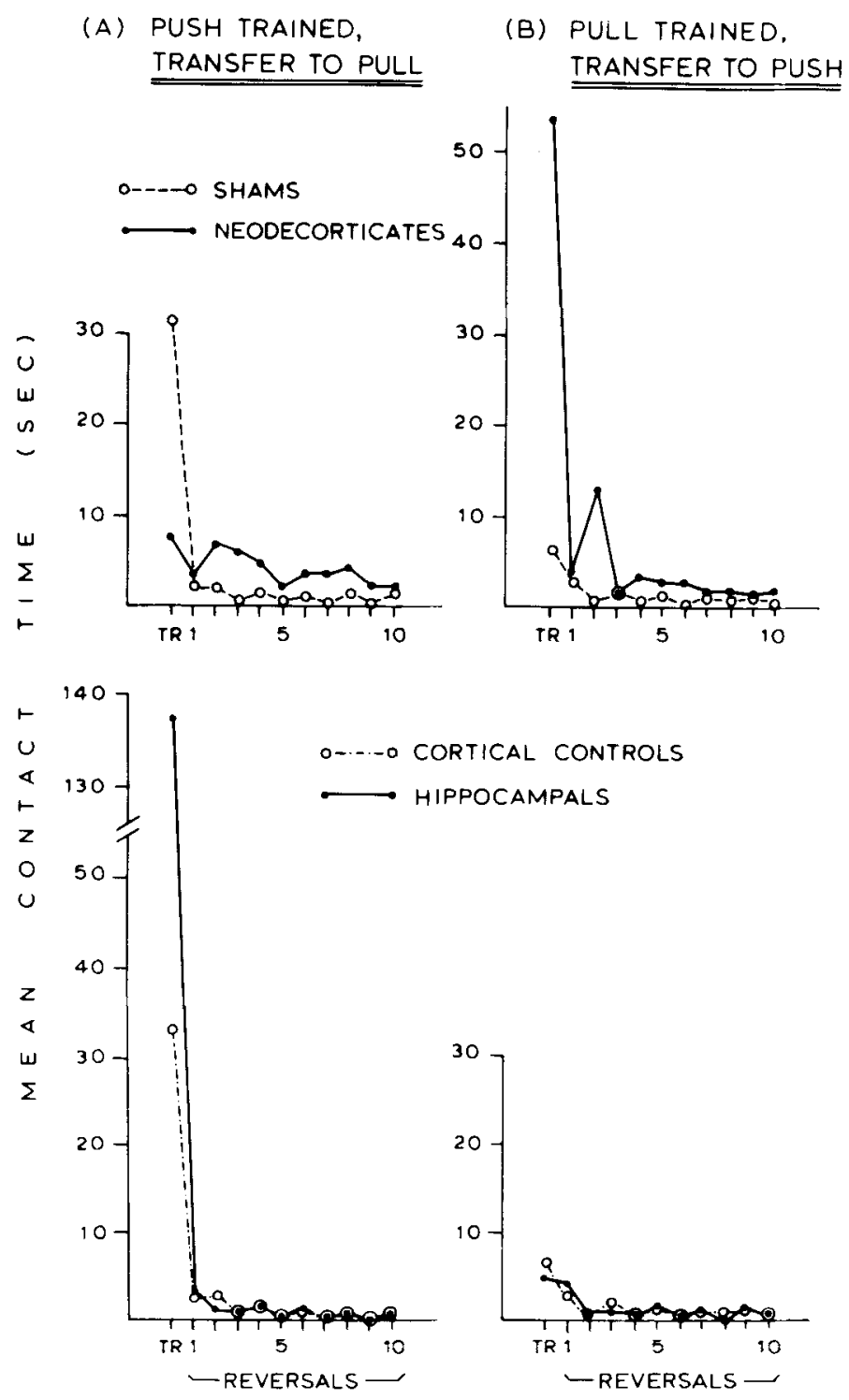

Figure 5. Mean contact times for each lesion group on critical transfer trial (TR) and on 10 subsequent reversal trials.

when pulling is the second response to be learned. A series of trend tests were performed on push errors over reversals in push-trained animals, and on pull errors over reversals after pull training. Using Page's $L$ test for monotonic trend (Page, 1963), for push errors after push training, $L=433.5, p<.01$; for pull errors after pull training, $L=1,465.0, p<.01$. The increase in pull errors over reversals after push training did not constitute a significant trend $[L=243.5, p>.05]$.

\section{DISCUSSION}

The neodecorticates demonstrated superior transfer profiles in comparison with the shams when required to shift from pushing to pulling, but they were inferior on the transfer from pulling to pushing. In both cases, the neo- decorticates were able to reverse competently between responses over subsequent sessions. They were also able to eliminate errors of the trained response when the alternative response was required. The hippocampals demonstrated a deficit only on transfer from pushing to pulling, the converse of the performance pattern shown by the neodecorticates.

The partitioning of perseverative and novel components demonstrated that the neodecorticate between-task transfer effect arose through differences in rates of perseverative responding; that is, perseveration occurred when the pretrained response was pull, but not when it was push. Novel responses occurred at a similar (low) level under both training conditions. From observation, neodecorticate response transfer from pull to push appeared disorganized and chaotic. By contrast, transfer after push 


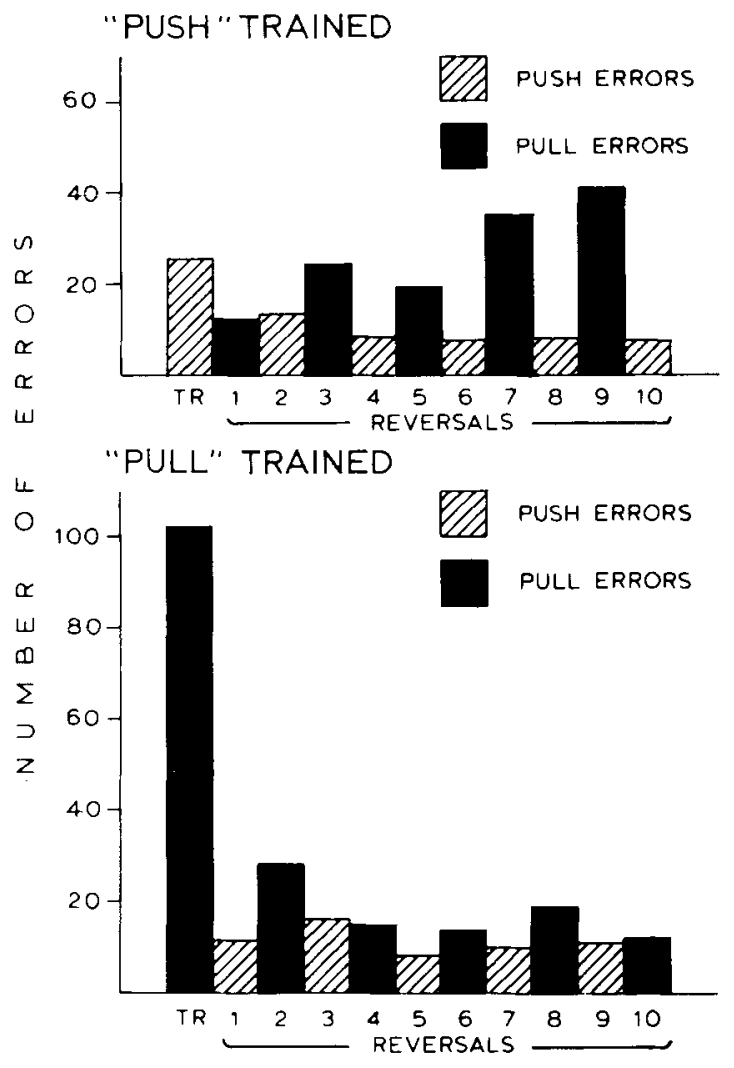

Figure 6. Mean numbers of erroneous responses emitted per session by the neodecorticates. Errors are summed across the last 15 trials of the transfer session (TR) and of the subsequent 10 reversal sessions.

training often appeared surprisingly adroit and wellcoordinated. By the third trial after transfer, the two responses were typically well differentiated. None of the other lesion groups showed clear, qualitative differences from the shams in terms of general transfer responding.

Thus the transfer-trial results for the neodecorticates, both quantitatively and qualitatively, are in accordance with those previously obtained (Terry et al., 1989). The asymmetry of transfer performance recurred even though the stabilization/reversal (terminal response) positions were equated between tasks. Hence explanations of the effect based on asymmetries in the locus of obstruction may be dismissed. Perhaps of particular significance, the neodecorticate pull-to-push transfer impairment recurred despite the elimination of a pull-acquisition deficit; this result argues against explanations that might relate neodecorticate response perseveration (previously) to an overtraining of the initial response. The absence of a neodecorticate pull-acquisition deficit is of further relevance with respect to neodecorticate response-learning processes in general. Thus, since the neodecorticates successfully acquired a pull response from a stabilized ball position as far from the alleyway entrance as that at which they formerly showed a substantial deficit, the change in training procedures between studies must be the salient factor in overcoming the impairment. The difference between procedures occurred in the rate at which the reorganization of a developing response had to occur. This fits with studies that emphasize the efficacy of small-increment shaping or the use of pretraining procedures to assist in establishing instrumental responses in neodecorticates (Oakley, 1979a, 1980; Oakley \& Russell, 1978a). In this respect, it is worth noting that the neodecorticates' pullclearance behavior at the first two to three ball positions in the alleyway still appeared fortuitous and undirected, although this initially "undirected" activity developed into an increasingly efficient and discrete pull response within the first training session. The neodecorticates were alone in frequently clambering over the ball rather than detouring around it, particularly in the startbox after successfully pulling the ball clear. Although inappropriate, this act often revealed great dexterity, and, despite the implication of response stereotypy, these rats turned into the alleyway from left or right, and also showed no stereotypical cup-approach behavior.

One aspect of neodecorticate performance still requires explanation: the asymmetric transfer effect. A possible clue as to the cause may be found in the observation that the push-trained neodecorticates often emit unnecessary pull-type paw manipulations of the ball during push stabilization. It is important to note, however, that such a tendency is not a prerequisite for efficient push-to-pull transfer, since rapid transfer was achieved by one neodecorticate which never produced such responses. Nevertheless, paw manipulations of the ball were not observed in any other group during push training or stabilization, and no rat outside the neodecorticate push-trained group transferred at a similar rate to the neodecorticates. It is already well established that neodecorticates present a number of abnormal motor responses that intrude into a variety of situations (Whishaw, Schallert, \& Kolb, 1981).

An explanation of the performance of the push-trained neodecorticates, incorporating this factor, may be developed. In moving from alleyway pretraining to push training, minimal response change is necessary; to continue to run the length of the tube still clears a path to the reinforcer. Extended push training (including stabilization) may serve to direct attention to the ball as an object to be manipulated, and this may allow the emergence of a preferred reaction to obstruction-a scrabbling action. Indeed, autoshaping may play a part here, since the placement of the ball ahead of the rat reliably predicts the availability of water, and this may predispose the displacement of goal-directed actions to the ball. Neodecorticates have been shown to autoshape more readily than shams (Oakley, Eames, Jacobs, Davey, \& Cleland, 1981). The prevention of the push response at transfer allows the clearer expression of the preferred or autoshaped response (primarily, pulling), and so to rapid success. However, in the pull-trained group, the shift from alleyway pretraining to pull training demands a considerable modification in ongoing behavior. Although pulling is a characteristic 
neodecorticate response to obstruction or frustration, the neodecorticates are initially unable to identify the ball as a salient, manipulable object. Over the course of a gradual and incremental shaping procedure (as in this study) the neodecorticate learns to direct its preferred response (pull) to the relevant manipulandum. This process tends to be disrupted if the shaping increments demand sudden and substantial reorganizations of behavior; under these conditions, the animal may, over repeated sessions, learn not to respond when confronted with stimuli previously associated with failure and nonreward (Terry et al., 1989). Because pulling is a characteristic and preferred neodecorticate response, the shift to pushing on pull-to-push transfer is hindered. The hypothesis thus explains both acquisition and transfer profiles.

The results in general concerning neodecorticate response learning and reversal do not conflict with those in previous studies, but rather extend them in a context of more complex response learning. Thus, the finding of competent neodecorticate reversal performance is in accordance with the fact that neodecorticates can demonstrate spatial reversal learning (Kolb \& Whishaw, 1981), albeit their performance appears much less retarded in these tasks. Moreover, the explanation given above to account for the observed patterns of response learning and transfer need not require substantial reevaluation of the residual flexibility following neodecortication. Indeed, performance may still be interpreted within the framework of associative learning (Oakley, 1983). Nevertheless, posttransfer reversals, patterns of error reduction, and the behavioral observations still indicate considerable behavioral flexibility, and the question remains as to the role of the neocortex in instrumental learning. Ironically, given the severity of neural loss, the requirement seems to be for more observations of irreversible and absolute learning decrements following neodecortication. To date, the only task that neodecorticates appear to find insoluble is place-learning in the Morris water maze, which leads to the suggestion that the cortex is required for the assimilation of distal, but not proximal, information (Whishaw \& Kolb, 1984). Such an interpretation could account for the present results, as could Oakley's (1983) broader hypothesis that the neocortex provides a substrate for nonassociative representational processes. These views are not incompatible, and more explicit empirical tests at the limits of neodecorticate learning will be required for a clearer determination of the essential contribution of the neocortex to learning in general.

\section{Hippocampals}

The hippocampals were included because their characteristic behavioral syndromes are often interpreted as being, at least in part, the product of impaired response control. It was considered important to determine whether rats with well-documented response control deficits would, in this procedure, produce results qualitatively or quantitatively similar to those of the neodecorticates, whose massive cortical loss would be expected to cause severe response-control difficulties. The hippocampals showed a significant deficit only on the initial transfer from pushing to pulling. Their transfer and reversal profiles were otherwise qualitatively similar to those of the shams and cortical controls. There was no relationship between lesion size and degree of transfer impairment. Posttransfer changes followed the patterns of the shams and cortical controls, as did patterns of within-session errors.

The performances of the shams and cortical controls were in close accord throughout. Also, it is to be noted that none of the between-group differences described above can be readily interpreted in terms of motivational factors, since there were no differences either in quantities of water intake postsession, or in profiles of weight change over the course of the experiment.

\section{Conclusion}

The results indicate that neodecorticates can acquire complex motor skills if behavioral shaping is gradual, and they show a marked discrepancy in transfer capabilities according to the ordering of trained and to-be-acquired responses. Neodecorticates can also reverse competently between motor responses, reducing erroneous attempts at the trained response. Hippocampals show an impairment in only one direction of response transfer, but this is not the one that neodecorticates find difficult; retardation at transfer (in either hippocampals or neodecorticates) is specific to the initial response transfer; subsequent reversal performance is competent for all groups. Overall, the results imply a greater degree of behavioral flexibility than had previously been supposed in the absence of the neocortex, and they suggest that neocortical and hippocampal lesions can lead to considerably different profiles of response learning and transfer.

\section{REFERENCES}

Boyd, M. G., \& Thomas, R. K. (1977). Posterior association cortex lesions in rats: Mazes, pattern discrimination and reversal learning. Physiological Psychology, 5, 455-461.

Devenport, L. D., Hale, R. L., \& Stibham, J. A. (1988). Sampling behavior in the radial maze and operant chamber: Role of the hippocampus and prefrontal area. Behavioral Neuroscience, 102, 489-498.

Einon, D. F., Morgan, M. J., \& WiLL, B. E. (1980). Effects of postoperative environment on recovery from dorsal hippocampal lesions in young rats: Spatial memory and motor transfer. Quarterly Journal of Experimental Psychology, 32, 137-148.

Gentile, A. M., Green, S., Nieburgs, A., Schmeltzer, W., \& Stein, D. G. (1978). Disruption and recovery of locomotor and manipulatory behavior following cortical lesions in rats. Behavioral Biology, $22,417-455$.

HiRSH, R. (1970). Lack of variability or perseveration: Describing the effects of hippocampal ablation. Physiology \& Behavior, 5, 1249-1254.

Kimble, D. P., \& Kimble, R. J. (1965). Hippocampectomy and response perseveration in the rat. Journal of Comparative \& Physiological Psychology, 60, 472-476.

Kolb, B., Nonneman, A. J., \& Singh, R. K. (1974). Double dissociation of spatial impairments and perseveration following selective prefrontal lesions in rats. Journal of Comparative \& Physiological Psychology, 87, 772-780.

Kolb, B., Sutherland, R. J., \& Whishaw, I. Q. (1983). A compari- 
son of the contributions of the frontal and parietal association cortex to spatial localization in the rat. Behavioral Neuroscience, 97, 13-27.

Kolb, B., \& Wishaw, I. Q. (1981). Decortication of rats in infancy or adulthood produces comparable functional losses on learned and species-typical behaviors. Journal of Comparative \& Physiological Psychology, 95, 468-483.

Kolb, B., \& WhISHAW, I. Q. (1983). Dissociation of the contributions of the prefrontal, motor, and parietal cortex to the control of movement in the rat: An experimental review. Canadian Journal of Psychology, 37, 211-232.

KRECHEVSKY, I. (1935). Brain mechanisms and "hypotheses." Journal of Comparative Psychology, 19, 425-468.

KRECHEVSKY, I. (1937). Brain mechanisms and variability: I. Variability within a means-end-readiness. Joumal of Comparative Psychology, 23, 121-138.

KRECHEVSKY, I. (1938). Brain mechanisms and "umweg" behavior. Journal of Comparative Psychology, 25, 147-173.

LASHLEY, K. S. (1929). Brain mechanisms and intelligence. Chicago: University of Chicago Press.

LASHLEY, K. S. (1935). Studies of cerebral functioning in learning: The behavior of the rat in latch box situations. Comparative Psychology Monographs, 11(2), 5-40.

MEYER, P. M., \& MEYER, D. R. (1971). Neurosurgical procedures with special reference to aspiration lesions. In R. D. Myers (Ed.), Methods in psychobiology (Vol. 1, pp. 91-130). London: Academic Press.

MorGaN, M. J. (1973). Effects of the post-weaning environment on learning in the rat. Animal Behavior, 21, 429-442.

Morgan, M. J., Einon, D. F., \& Morris, R. G. M. (1977). Inhibition and isolation rearing in the rat: Extinction and satiation. Physiology \& Behavior, 18, 1-5.

Nikı, H. (1965). The effect of hippocampal ablation on the inhibitory control of operant behavior in the rat. Japanese Psychological Research, 7, 126-137.

NumaN, R. (1978). Cortical-limbic mechanisms and response control: A theoretical review, Physiological Psychology, 6, 445-470.

OAKLEY, D. A. (1979a). Instrumental reversal learning and subsequent fixed-ratio performance on simple and go/no-go schedules in neodecorticate rabbits. Physiological Psychology, 7, 29-42.

OAKLFY, D. A. (1979b). Learning with food reward and shock avoidance in neodecorticate rats. Experimental Neurology, 63, 627-642.

OAKLEY, D. A. (1980). Improved instrumental learning in neodecorticate rats. Physiology \& Behavior, 24, 357-366.

OAKLEY, D. A. (1983). The varieties of memory: A phylogenetic approach. In A. Mayes (Ed.), Memory in animals and humans (pp. 2081). Wokingham, England: Van Nostrand Reinhold.

Oakley, D. A., Eames, L. C., Jacobs, J. L., Davey, G., \& Cleland, G. (1981). Signal-centered action patterns in rats without neocortex in a Paviovian conditioning situation. Physiological Psychology, 9, 135-144.

OAKLey, D. A., \& Russell, I. S. (1972). Neocortical lesions and Pavlovian conditioning. Physiology \& Behavior, 8, 915-926
OAKLey, D. A., RusSell, I. S. (1974). Differential and reversal conditioning in partially neodecorticate rabbits. Physiology \& Behavior, 3, 221-230.

OAKLey, D. A., \& Russell, I. S. (1975). Role of cortex in Pavlovian discrimination learning. Physiology \& Behavior, 15, 315-321.

OAkLey, D. A., \& Russell, I. S. (1976). Subcortical nature of Pavlovian differentiation in the rabbit. Physiology \& Behavior, 17, 947-954.

OAkLey, D. A., \& Russell, I. S. (1977). Subcortical storage of Pavlovian conditioning in the rabbit. Physiology \& Behavior, 18, 931-937.

OAKLey, D. A., \&ussell, I. S. (1978a). Manipulandum identification in operant behaviour in neodecorticate rabbits. Physiology \& Behavior, 21, 943-950.

OAKLeY, D. A., \&ussell, I. S. (1978b). Performance of neodecorticated rabbits in a free-operant situation. Physiology \& Behavior, 20, 157-170.

OAKLey, D. A., \& Russell, I. S. (1980). Effect of prior experience on bar pressing in rats without neocortex. Behavioural Brain Research, 1, 267-283.

PAGE, E. B. (1963). Ordered hypotheses for multiple treatments: A significance test for linear ranks. Joumal of the American Statistical Association, 58, 216-230.

Riopelle, A. J. (1967). Animal problem solving. Baltimore: Penguin. Sutherland, R. J., Kol,B, B., \& Whishaw, I. Q. (1982). Spatial mapping: Definitive disruption by hippocampal or medial frontal damage in the rat. Neuroscience Letters, 31, 271-276.

Teitelbaum, H. A. (1964). A comparison of the effects of orbitofrontal and hippocampal lesions upon discrimination learning and reversal in the cat. Experimental Neurology, 9, 452-462.

Terry, P., Herbert, B. A., \& Onkley, D. A. (1989). Anomalous patterns of response learning and transfer in decorticate rats. Behavioural Brain Research, 33, 105-109.

Thомas, R. K., Weir, V. K. (1975). The effects of lesions in the frontal or posterior association cortex of rats on maze III. Physiological Psychology, 3, 210-214.

Thompson, R., Gallardo, K., \& Yu, J. (1984). Cortical mechanisms underlying acquisition of latch-box problems in the white rat. Physiology \& Behavior, 32, 809.817.

Thompson, R., HARMon, D., \&u, J. (1984a). Detour problem-solving behavior in rats with early lesions to the "general learning system." Physiological Psychology, 12, 193-204.

Thompson, R., HARMon, D., \& Yu, J. (1984b). Detour problem-solving behavior in rats with neocortical and hippocampal lesions: A study of response flexibility. Physiological Psychology, 12, 116-124.

Whishaw, I. Q., \& KoLB, B. (1984). Decortication abolishes place but not cue learning in rats. Behavioural Brain Research, 11, 123-134.

Whishaw, I. Q., Schallert, T., KolB, B. (1981). An analysis of feeding and sensorimotor abilities of rats after decortication. Journal of Comparative \& Physiological Psychology, 95, 85-103.

(Manuscript received November 17, 1989; revision accepted for publication May 7,1990 .) 